\title{
Variability of Extreme Wet Events over Malawi
}

\author{
Brigadier LibandaA*, Mie ZhengA ${ }^{\mathrm{A}}$, Noel Banda ${ }^{\mathrm{B}}$ \\ Received: July 31, 2017 | Revised: September 16, 2017 | Accepted: September 21, 2017
}

DOI: 10.5937/gp21-16075

\begin{abstract}
Adverse effects of extreme wet events are well documented by several studies around the world. These effects are exacerbated in developing countries like Malawi that have insufficient risk reduction strategies and capacity to cope with extreme wet weather. Ardent monitoring of the variability of extreme wet events over Malawi is therefore imperative. The use of the Expert Team on Climate Change Detection and Indices (ETCCDI) has been recommended by many studies as an effective way of quantifying extreme wet events. In this study, ETCCDI indices were used to examine the number of heavy, very heavy, and extremely heavy rainfall days; daily and five-day maximum rainfall; very wet and extremely wet days; annual wet days and simple daily intensity. The Standard Normal Homogeneity Test (SNHT) was employed at $5 \%$ significance level before any statistical test was done. Trend analysis was done using the nonparametric Mann-Kendall statistical test. All stations were found to be homogeneous apart from Mimosa. Trend results show high temporal and spatial variability with the only significant results being: increase in daily maximum rainfall (Rx1day) over Karonga and Bvumbwe, increase in five-day maximum rainfall (Rx5day) over Bvumbwe. Mzimba and Chileka recorded a significant decrease in very wet days (R95P) while a significant increase was observed over Thyolo. Chileka was the only station which observed a significant trend (decrease) in extremely wet rainfall (R99p). Mzimba was the only station that reported a significant trend (decrease) in annual wet-day rainfall total (PRCPTOT) and Thyolo was the only station that reported a significant trend (increase) in simple daily intensity (SDII). Furthermore, the findings of this study revealed that, during wet years, Malawi is characterised by an anomalous convergence of strong south-easterly and north-easterly winds. This convergence is the main rain bringing mechanism to Malawi.
\end{abstract}

Key Words: Extreme wet events, frequency, rainfall intensity, Malawi, Africa

\section{Introduction}

In recent years, there is generally a consensus on the fact that the climate is changing (Intergovernmental Panel on Climate Change, IPCC 2014) in part due to human influences (Kaser, et al., 2010). Contributing to the IPCC's Fifth Assessment Report, Working Group II (WGII AR5), documents that human-induced climate change expedites and worsens climate variations and change that would otherwise occur naturally (IPCC, 2014; Bouwer, et al., 2011). Evidences of the changing climate have been shown by observations of the atmosphere, land, oceans and cryosphere (IPCC, 2013; Bouwer, et al., 2011). In previous studies, the IPCC has shown that the atmospheric global mean temperatures over land and oceans have increased by $0.85^{\circ} \mathrm{C}$ over the last hundred years (IPCC, 2001). This temperature change in the longrun affects the global water cycle, altering the inten-

\footnotetext{
A School of Civil Engineering and Geosciences, Newcastle University, United Kingdom

B Malawi Department of Climate Change and Meteorological Services

* Corresponding author: Brigadier Libanda, e-mail: brigadierlibanda@rocketmail.com, b.libanda2@newcastle.ac.uk, ORCID: 0000-0001-8215-5572, phone: +4407823467718
} 
sity, frequency and amount of precipitation (Sylla, et al., 2012).

Climate change will increase uncertainty and exert adverse effects on water security, agricultural planning, analysis of flood intensity and frequency, climatological and hydrological modelling, mapping of floods and flood risk in developing countries (IPCC, 2012). This is because developing countries have little ability to 'bounce back' from hostile impacts of climate change. A study published in Nature by Vorosmarty et al. (2010), showed that estimated future impacts of climate change would be worse in some developed regions than developing ones. However, this was reversed when the ability of a country to 'bounce back' was taken into consideration. In a study of the challenge of feeding a world population of more than eight billion people, Loomis et al. argues that developing countries will be affected more by the impacts of climate change owing to their heavy reliance on weather and climate sensitive sectors such as rain-fed agriculture (Loomis, et al., 1999). This sector is affected by both negative and positive extreme weather events; understanding the variability of extremes is thus, the primary protection against climate change-induced disasters (Westra, et al., 2014). Most Global Circulation Models (GCMs) ensembles' predictions indicate a more wet than dry trend over much of the north-eastern parts of southern Africa including Malawi and a more dry than wet trend over the southern parts of Malawi; most of these simulations agree on the trend direction but not magnitude (Christensen, et al., 2007).

Extreme wet events are common in Malawi (Karl, et al., 2010a). For example, in January 2015, 150 people were feared dead after a heavy downpour of rainfall and 100, ooo more were displaced after the same wet event and many people were reported as having crossed to neighbouring Mozambique to seek refuge (BBC, 2015). In April 2016, low-lying areas of Malawi were again flooded leaving 12 people dead and 9000 displaced in Ngosi, Karonga and Mzuzu. This was after a heavy downpour of $143 \mathrm{~mm}$ in 24 hours (Juma, 2017) which is an equivalent of the rainfall amount received in some months. More recently ( $4^{\text {th }}$ April 2017), floodprone Karonga was again hit by extreme wet weather leaving 5,520 households adversely affected and about 1075 hectares of crops fields, including rice, maize and cassava, severely damaged (Davies, 2017). Many other studies have shown detailed evidence that the impacts of extremes are exacerbated due to Malawi's over-dependence on rain-fed agriculture just like many other southern African countries such as Zambia (Libanda, et al. 2017). In fact, half of Malawi's gross domestic products (GDP) are directly or indirectly from agriculture (Benin, et al., 2008). Ngongondo et al. described Malawi as an agro-based economy with the majority of its agricultural produce being rain-fed (Ngongondo, et al., 2011). In a discussion paper on the economic effects of droughts and floods in Malawi, Karl et al. estimated that Malawi loses US $\$ 22$ million of its GDP annually due to extreme weather events (Karl, et al., 2010). Thus, the World Bank classifies Malawi and the whole of sub-Saharan Africa as highly vulnerable to climate change (Benson, et al., 1998). A project (ND-GAIN) by the University of Notre Dame which investigates a country's vulnerability to climate change and its readiness to improve resilience ranks Malawi as the thirty ninth most vulnerable country and the twenty-first least ready country (ND-GAIN, 2017).

While understanding changes in mean rainfall climatology is necessary (Libanda, et al., 2015a), this study focuses on extremes due to their detrimental effects on socio-economic activities of Malawi (Karl, et al., 2013b). An understanding of extremes also strengthens the ability to predict them. Studies (e.g. Nicholas, et al., 2017) have also shown that that many professions, inter alia water resource engineers, hydrologists, civil and structural engineers are keen to understand projections of extremes because future designs e.g. flood detention facilities, hydroelectricity supply, bridges etc are highly dependent on reliable understanding of extremes. Mokrech, et al. documents that extremes distort the natural balance of ecosystems, structural designs are meant to be able to withstand floods, a good understanding of these extremes offsets uncertainties inherent in socio-economic activities and play a central role in strategizing mitigating approaches (Mokrech, et al., 2014). Therefore, investigating extremes underpins development. The goal of this study was to investigate extreme wet events for the period $1982-2012$ using ETCCDI Indices. Particularly, the indices were grouped to represent intensity (number of heavy rainfall days, very heavy rainfall days and extremely heavy rainfall days) and frequency (daily maximum rainfall, 5-day maximum rainfall, annual-wet day rainfall total, simple daily intensity index, very wet days and extremely wet days). Extremes considered in this study are with respect to the amount of precipitation over a given area and exceeding a given daily rainfall amount, daily maxima and/or percentile. Detailed definitions of the extreme indices used herein are discussed by (Karl, et al., 1999).

\section{Data and Methodology}

\section{Sources of data}

The daily rainfall data used in this study is courtesy of the Malawi Department of Climate Change and Meteorological Services (MDCCMS). The data covers a period of thirty years from $1982-2012$ and is 


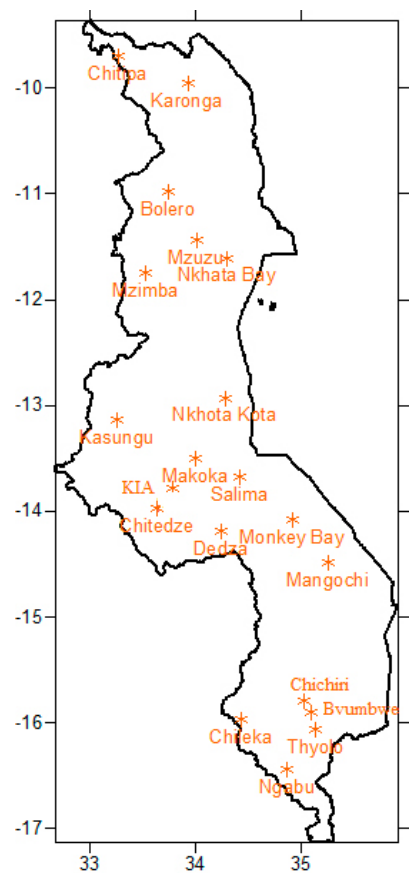

Figure 1. Meteorological Stations used in this study

sourced from 21 Meteorological Stations (i.e. synoptic, agro and aviation meteorological stations) widely spread over the whole country. However, the datasets for Thyolo Meteorological Stations only spans over a period of 27 years from $1982-2009$ (Table 1). Figure 1 shows the geographical spread of the Meteorological stations used in this study.

\section{Methodology}

\section{Extreme rainfall indices}

Previous studies have analysed daily extreme rainfall by using indices as proposed by the Expert Team on Climate Change Detection and Indices (ETCCDI), a joint team of the World Meteorological Organization (WMO), Climate Change Initiative $(\mathrm{CCl})$, Climate Variability and Predictability (CLIVAR) and the Joint Technical Commission for Oceanography and Marine Meteorology (JCOMM). This joint task force was formed following the CLIVAR/GCOS/ WMO workshop on indices and indicators for climate extremes. A summary of the CLIVAR/GCOS/ WMO workshop on ETCCDI indices is documented by (Karl, et al., 1999).

This study utilized nine (Table 2) of the ETCCDI indices to understand the behaviour of extreme wet events over Malawi during the period $1982-2012$.

Table 1. Period of rainfall data used and climatology for each station. Mimosa was not included in the analysis for being inhomogeneous.

\begin{tabular}{|c|c|c|c|c|c|}
\hline $\begin{array}{l}\text { Meteorological } \\
\text { Station }\end{array}$ & Period of Data & Mean (mm) & $\operatorname{Max}(\mathrm{mm})$ & $\operatorname{Min}(\mathrm{mm})$ & $\begin{array}{l}\text { Standard } \\
\text { Deviation }\end{array}$ \\
\hline Bolero & 1982 - 2012 & 629.6 & 924.7 & 370.7 & 139.9 \\
\hline Bvumbwe & $1982-2012$ & 1153.5 & 1887.9 & 745.8 & 265.6 \\
\hline Chichiri & $1982-2012$ & 1117.7 & 1678.1 & 674 & 272.6 \\
\hline Chileka & 1982 - 2012 & 857.6 & 1290.9 & 506.8 & 205.6 \\
\hline Chitedze & $1982-2012$ & 858.8 & 1201.4 & 281.9 & 205.8 \\
\hline Chitipa & 1982 - 2012 & 928.2 & 1369.2 & 696.8 & 162.9 \\
\hline Dedza & $1982-2012$ & 933.1 & 1504.1 & 568.7 & 208.9 \\
\hline Karonga & 1982 - 2012 & 946.7 & 1514.4 & 638.8 & 238.9 \\
\hline Kasungu & 1982 - 2012 & 770.6 & 1309.9 & 456.2 & 181.3 \\
\hline $\mathrm{KIA}$ & $1982-2012$ & 825 & 1306.7 & 546.3 & 173.1 \\
\hline Makoka & 1982 - 2012 & 1001.5 & 1516 & 417.2 & 251.5 \\
\hline Mangonchi & $1982-2012$ & 726 & 1240.5 & 246.5 & 231.2 \\
\hline Monkey BAY & 1982 - 2012 & 835.4 & 1358.6 & 387.5 & 247.5 \\
\hline Mzimba & 1982 - 2012 & 833.7 & 1339.4 & 572.1 & 161.3 \\
\hline Mzuzu & 1982 - 2012 & 928.2 & 1369.2 & 696.8 & 162.9 \\
\hline Ngabu & 1982 - 2012 & 782.8 & 1261.7 & 414.1 & 251 \\
\hline Nkhata Bay & $1982-2012$ & 1521.4 & 2465.6 & 862.9 & 381.4 \\
\hline Nkhota Kota & 1982 - 2012 & 1330 & 1961.4 & 860.2 & 287.3 \\
\hline Salima & 1982 - 2012 & 1192.3 & 2018.7 & 409.3 & 370.1 \\
\hline Thyolo & $1982-2009$ & 1226.1 & 1808.4 & 746.6 & 298.4 \\
\hline Mimosa & 1982 - 2012 & & & & \\
\hline
\end{tabular}


Table 2. Indices used in this study.

\begin{tabular}{|c|c|c|c|c|}
\hline Indices & Name & Indices Calculation & Definition & Unit \\
\hline R10mm & $\begin{array}{l}\text { Number of heavy } \\
\text { rainfall days }\end{array}$ & $R R i j \geq 10 \mathrm{~mm}$ & $\begin{array}{l}\text { Annual count of days } \\
\text { when days rainfall } \geq 10 \\
\mathrm{~mm}\end{array}$ & Days \\
\hline R20mm & $\begin{array}{c}\text { Number of very heavy } \\
\text { rainfall days }\end{array}$ & $R R i j \geq 20 \mathrm{~mm}$ & $\begin{array}{l}\text { Annual count of days when } \\
\text { days rainfall } \geq 20 \mathrm{~mm}\end{array}$ & Days \\
\hline $\mathrm{R} 25 \mathrm{~mm}$ & $\begin{array}{l}\text { Number of extremely } \\
\text { heavy rainfall days }\end{array}$ & $R R i j \geq 25 \mathrm{~mm}$ & $\begin{array}{l}\text { Annual count of days when } \\
\text { days rainfall } \geq 25 \mathrm{~mm}\end{array}$ & Days \\
\hline RX1day & $\begin{array}{l}\text { Daily maximum } \\
\text { rainfall }\end{array}$ & $R x 1 d a y j=\max (R R i j)$ & $\begin{array}{l}\text { Monthly maximum 1-day } \\
\text { rainfall }\end{array}$ & $\mathrm{mm}$ \\
\hline RX5day & $\begin{array}{l}\text { 5-day maximum } \\
\text { rainfall }\end{array}$ & $R x 5$ day $j=\max (R R i j)$ & $\begin{array}{l}\text { Monthly maximum 5-day } \\
\text { rainfall }\end{array}$ & $\mathrm{mm}$ \\
\hline PRCPTOT & $\begin{array}{l}\text { Annual wet-day } \\
\text { rainfall total }\end{array}$ & PRCPTOTj $=\sum_{i=1}^{i} R R i j$ & $\begin{array}{c}\text { Annual total rainfall in wet } \\
\text { day }(\mathrm{RR}>1 \mathrm{~mm})\end{array}$ & $\mathrm{mm}$ \\
\hline SDII & $\begin{array}{l}\text { Simple daily intensity } \\
\text { index }\end{array}$ & $S D I I_{j}=\frac{\sum_{W=1}^{W} R R_{j}}{W}$ & $\begin{array}{l}\text { Annual mean rainfall when } \\
\qquad P R C P \geq 1 \mathrm{~mm}\end{array}$ & $\mathrm{~mm} /$ day \\
\hline R95p & Very wet day & $R 95 p_{j}=\sum_{W=1}^{W} R R_{w j}$ & $\begin{array}{l}\text { Annual total rainfall when } \\
\qquad R R>95 \text { percentile }\end{array}$ & $\mathrm{mm}$ \\
\hline R99p & Extremely wet day & $R 99 p_{j}=\sum_{W=1}^{W} R R_{w j}$ & $\begin{array}{l}\text { Annual total rainfall when } \\
\text { RR > } 99 \text { percentile }\end{array}$ & $\mathrm{mm}$ \\
\hline
\end{tabular}

$\mathrm{RR}=$ Rainfall on consecutive days.

\section{Homogeneity test}

Over the years, many approaches used for checking the homogeneity of rainfall data have been developed; in this study, following (Alexandersson, et al., 1977), Standard Normal Homogeneity Test (SNHT) was used to check the homogeneity of the daily rainfall series. The equations for computing the SNHT is shown below:

$$
T_{y}=y \overline{z_{1}}+(n-y) \overline{z_{2}}, y=1,2, \ldots n
$$

Where:

$$
\overline{z_{1}}=\frac{1}{y} \sum_{i=1}^{n} \frac{(Y i-\bar{Y})}{S} \text { and } \overline{z_{2}}=\frac{1}{n-y} \sum_{i=y+1}^{n} \frac{(Y i-\bar{Y})}{S}
$$

If the value of $T$ is maximum, the year of $y$ would be considered as having a break. The null hypothesis is rejected if the test

$$
T_{0}=\max _{1 \leq y \leq n} T_{y}
$$

is greater than the critical value, which is dependent on the size of the sample under consideration. Many studies (e.g. Javari, 2016; Kang, et al., 2012) have rec- ommended SNHT as a robust method of checking homogeneity of daily rainfall.

\section{Trend analysis}

To investigate trends in the observed daily rainfall over Malawi, a non-parametric Mann-Kendall test statistic was employed after (Mann, 1945) and (Kendall, 1975). The Mann-Kendall test does not need the data to be normally distributed. Furthermore, the Mann-Kendall test has a low sensitivity to missing data. A number of approaches have been developed to detect trends in timeseries. However, the Mann-Kendall test statistic is widely used by climatologists and Hydrologists. Mathematically, the Mann-Kendall test statistic is given as shown below:

$$
s=\sum_{i=1}^{n-1} \sum_{j=i+1}^{n} \operatorname{sig}\left(X_{i}-X_{j}\right)
$$

\section{Where:}

$n$ is the sample size $X_{i}$ and $X_{j}$ are sequential values of $X$. The $\mathrm{p}$-value after the Z-test has been used herein in comparison to the alpha $5 \%$ confidence level; if the p-value is lower (higher) than alpha then it is taken to be significant (insignificant). The hypothesis employed was: 
1. Null hypothesis $\left(H_{\mathrm{o}}\right)$ there is no trend in the series

2. Alternative hypothesis $\left(H_{1}\right)$ There is a trend in the series

Following (Sen, 1968), the slope estimator gives the magnitude of trends. Sen's slope estimator is a nonparametric approach, which assumes that the trend is linear. Multiple estimates $\left(N^{\prime}\right)$ of the slope can be determined using Sen's slope which is mathematically given as:

$Q=\frac{Y_{i^{\prime}}-Y_{i}}{i^{\prime}-i}$

Where:

- Q is a slope estimate.

- $Y_{i}^{\prime}$ are $Y_{i}$ the values at times i' and $i$, where $i$ ' is greater than $\mathrm{i}$,

- $\mathrm{N}^{\prime}$ is all data pairs for which $\mathrm{i}^{\prime}$ is greater than $\mathrm{i}$.

\section{The correlation coefficient ( $r$ )}

Pearson's correlation (r) was used to scrutinize the strength of the linear relationship (if any) between Mean December - February (DJF) wind anomaly vectors $\left(m^{-1}\right)$ at $850 \mathrm{hpa}$ and mean rainfall over Malawi. The Pearson correlation is obtained by dividing the covariance of the two variables by the product of their standard deviations and is thus given as:

$$
r=\frac{\sum_{i=1}^{n}\left(x_{i}-\bar{x}\right) \cdot\left(y_{i}-\bar{y}\right)}{\sqrt{\sum_{i=1}^{n}\left(x_{i}-\bar{x}\right)^{2} \cdot \sum_{i=1}^{n}\left(y_{i}-\bar{y}\right)^{2}}}
$$

1 is given if there is a perfect upward linear relationship, and -1 if there is a downward linear relationship, and the values in between indicate the magnitude of relationship between Mean DJF wind anomaly vectors $\left(m^{-1}\right)$ at $850 \mathrm{hpa}$ and mean rainfall over Malawi. A correlation coefficient of o means the no linear relationship exists (Yang, et al., 2005)

\section{Results and Discussion}

\section{Distribution and variability of rainfall over Malawi}

Malawi is located within the confines of latitudes $9^{\circ}$ and $15^{\circ} \mathrm{S}$ and longitudes $32-36^{\circ} \mathrm{E}$ and is completely surrounded by three countries: Zambia and Tanzania to the North and Mozambique to the south (figure 2). The topography of Malawi is mainly characterized by the Great Lift Valley. High points include Mount Mulanje at 3,048 meters and Mount Zomba at 2,133 meters. The lowest areas are mainly in the south of the country over the Shire and are in the range of 609 to 914 meters (Kumbuyo, et al., 2011).

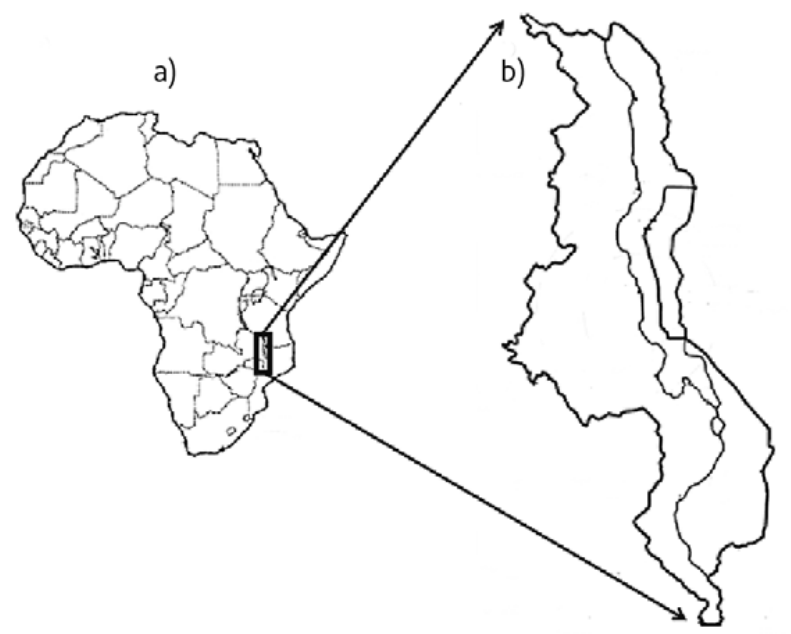

Figure 2. a) Location of Malawi (rectangle) on map of Africa b) map of Malawi

The country experiences a sub-tropical climate (Ngwira, et al., 2014). The core wet months over all the stations in Malawi have been observed to be November to April (figure 3) with over $90 \%$ of annual precipitation received during these months. The rain season is thus, clearly defined.

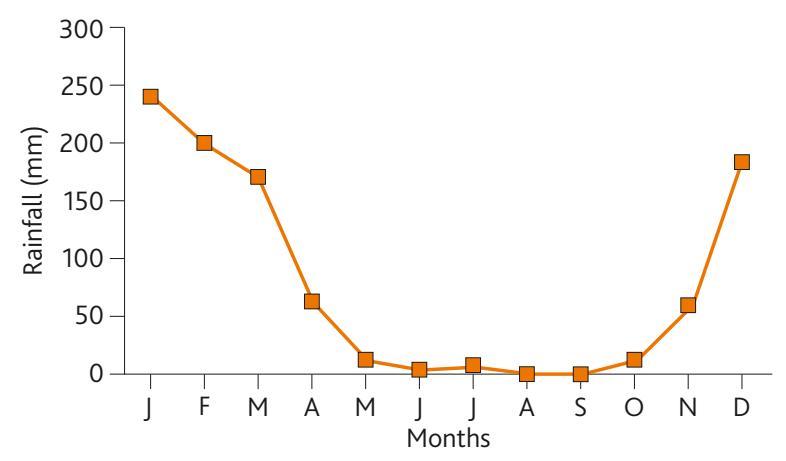

Figure 3. 1982 - 2012 annual rainfall cycle over Malawi

In a study on determining the onset and cessation of seasonal rains in Malawi, Kazembe et al. documents that the fluctuations of the Inter Tropical Convergence Zone (ITCZ) triggers the onset and offset of the rainy season in Malawi (Kazembe, et al., 2014). The ITCZ is a zone of convergence between the moist Congo air mass, the north-eastern trade winds and the meridional south-eastern trade winds (Libanda, et al., 2015b). The ITCZ oscillates over the country during the transition month of October to give Malawi it's first rains. it traverses southwards reaching Thyolo, Mulanje, Bvumbwe and surrounding areas at the end (beginning) of November (December) before retreating northwards at the end (beginning) of March (April) and thus, bringing the rainy season to a close and ushering in the cool dry season. Thus, the behaviour of the ITCZ gives Malawi a clear bimodal climatic pattern with three distinct seasons: cool dry (May to August), hot (August to November) and wet (No- 
vember to April). Jury and Mwafulirwa have also attributed the variations of Malawi's wet and dry seasons to tropical cyclones originating from the west of the India Ocean (Jury, et al., 2012). These cyclones have been found to cause spells of dryness or wetness depending on their location. Jury et al. also shows in a study on the variability in the tropical southwest Indian Ocean and influence on southern African climate that these systems bring widespread extreme rainfall and subsequent flooding over the Limpopo region in Malawi (Jury, et al., 2013). The bimodal climate pattern of Malawi has also been attributed to the teleconnections especially the El Nino Southern Oscillation (ENSO). Studies (e.g. Hoell, et al., 2014) have found that generally the Northern parts of the country, together with eastern African countries, experience extreme wetness during El Nino years while the southern parts experience extreme dryness. During La Nina years however, the southern half of the country together with southern African countries (e.g. Zambia) experience extreme wetness while the northern parts and eastern African countries experience extreme dryness (Ngongondo, et al., 2006). This observation will be key for agricultural tactical purposes especially considering that most models project wetness on the northern half of the country and dryness on the southern half. The choice of crops grown in each part of the country will have to be dependent not only on the soil type but on climatic conditions. Strategic planning will also have to be employed in the supply of electricity as over $90 \%$ of the country's electricity is hydro and powered from the river Shire in the southern part of the country (Benin, et al., 2008).

During the study period (1982 to 2012), more precipitation was received during December - February (DJF) than March to May (MAM) over Malawi. Offpeak (May to October) rains were observed to be highest over Nkhata Bay while the lowest was observed over Mzuzu. During the peak season (November to March), the highest rains were again recorded over Nkhata Bay, with a mean of $1521.4 \mathrm{~mm}$, received more rainfall than any other station in the country while the lowest (629.6 $\mathrm{mm}$ ) was reported over Bolero in the north of the country (Table 1). Nkhata Bay meteorological station also reported the highest maxima of $2018.7 \mathrm{~mm}$. These results are in agreement with rainfall patterns documented by the Malawi Department of Climate Change and Meteorological Services (Metmalawi, 2017).

While a definite uniform precipitation pattern (80o - $1000 \mathrm{~mm}$ ) has been observed in the central parts of the country from the north to the south (figure 4), the north-eastern parts of the country especially towards lake Malawi received more rainfall (above $1000 \mathrm{~mm}$ ) than the north-western parts (below $800 \mathrm{~mm}$ ) during the study period.

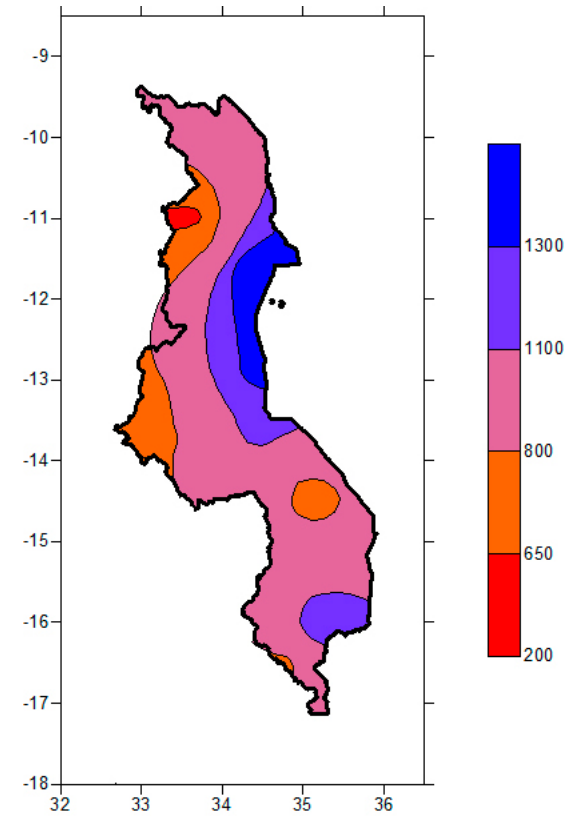

Figure 4. Distribution of annual mean rainfall ( $\mathrm{mm}$ ) over Malawi for the period $1982-2012$

The more rainfall received over the eastern parts of the country have been, in part, linked to the contribution that Lake Malawi makes over areas near it. Jury and Gwazantini also hinted that the variations in moisture transport from Lake Malawi have an impact on the rainfall pattern (Jury, et al., 2002). In a study on the evaluation of spatial and temporal characteristics of rainfall in Malawi, Ngongondo et al. classified the lake as a dominant water resources feature given it's large surface area of $2.8 \times 104$ i.e. two thirds of the country's total area (Ngongondo et al. 2012). Studies (e.g. Nicholson, et al., 200o) have shown that localised rainfall can be enhanced by the presence of major water bodies e.g. lakes. This is because evaporation is to a great extent dependent on the amount of available water (Majidi, et al. 2015). This is why evaporation is higher in tropical rainforests than in arid and semiarid regions. Studies (e.g. Lee, 2015) have also shown a direct link between evaporation and cloud formation which in turn leads to localized precipitation. Nicholson et al. also found that Lake Malawi exerts significant influence on the variations of precipitation (Nicholson, et al., 2013); in a similar study over Lakes Victoria and Tanganyika, Nicholson and Yin found that the two lakes boosted rainfall by 35 (Victoria) and 11\% (Lake Tanganyika) (Nicholson, et al., 2002). Further analysis showed that during wet years, Malawi is characterised by a convergence of strong south-easterly and north-easterly winds at $850 \mathrm{hpa}$. Convergence at low level boosts ascending motion which in turn enhances rainfall, hence wet years (e.g. 1989). However, during periods of extreme dryness, this convergence completely disappears. In this study, extreme wet year 
(a)WIND ANO(WET)

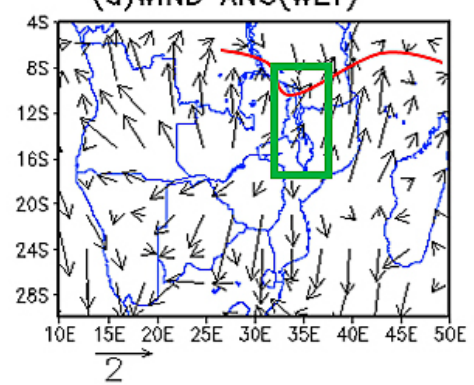

(b)WIND ANO(DRY)

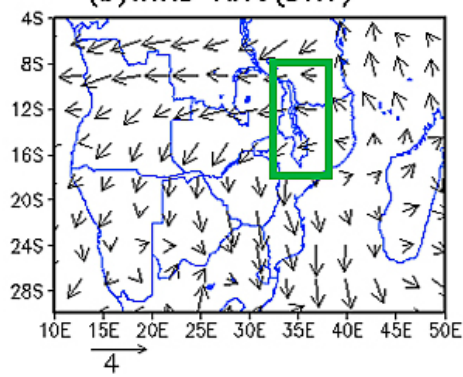

Figure 5. Mean DJF wind anomaly vectors $\left(\mathrm{m}^{-1}\right)$ at $850 \mathrm{hpa}$ a wet year (1989) and b dry year (2005), based on ERA-interim reanalysis data. Red curve on figure 5 a shows the anomalous convergence zone. The green rectangles show the geographical location of the study area

1989 (figure 5a) and extreme dry year 2005 (figure 5b) have been used to show this anomalous convergence during wet year and lack thereof during the dry year.

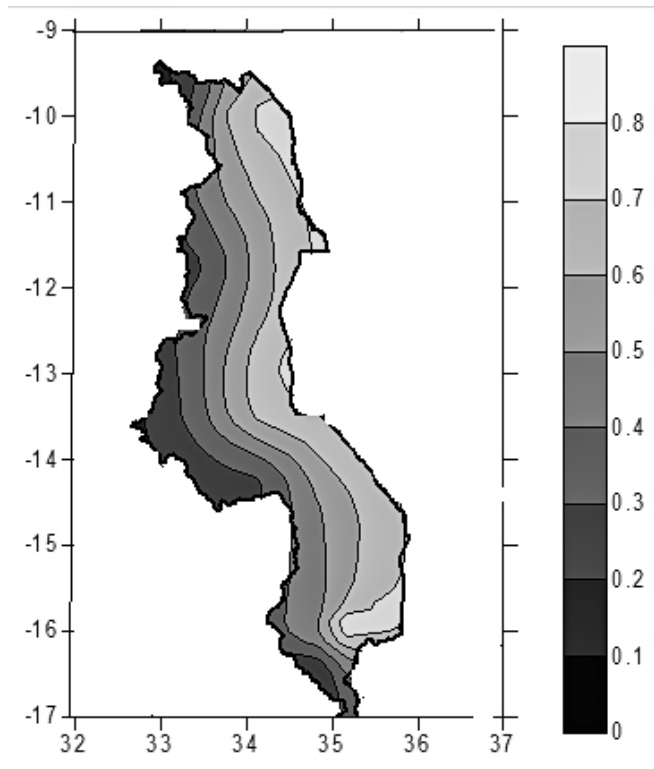

Figure 6. Spatial correlation between mean DJF wind anomaly vectors $\left(\mathrm{m}^{-1}\right)$ at $850 \mathrm{hpa}$ and mean rainfall over Malawi
Results of Pearson's correlation (figure 6) between mean DJF wind anomaly vectors $\left(\mathrm{m}^{-1}\right)$ at $850 \mathrm{hpa}$ and mean rainfall over Malawi show stronger correlation along the eastern parts of the country and weakens west-wards hence contributing to more precipitation on the eastern than on the western parts of the country.

Having removed influences of dispersion, the magnitude of rainfall anomalies during the period of study $(1982-2012)$ is given in figure 7 below. These results show that Malawi received more extreme negative years (exceeding -1) than positive ones (exceeding 1) with the most intense wet year being recorded in 1989 which was however followed by four years of below normal rainfall (1992 to 1995). With the exception of 1998 and 2005, from 1996 to 2010, precipitation was generally above normal over most of the stations in Malawi. While antecedent conditions of a given region play a role in triggering floods, above normal rainfall is regarded by many studies (e.g. Zaroug, et al. 2014) as a key driver of floods. In a similar study on extreme events over Uganda, Ogwang et al. shows that standardized anomaly can be used as a measure of how intense an extreme event was with showing extreme wetness while $\leq-1$ showing extreme

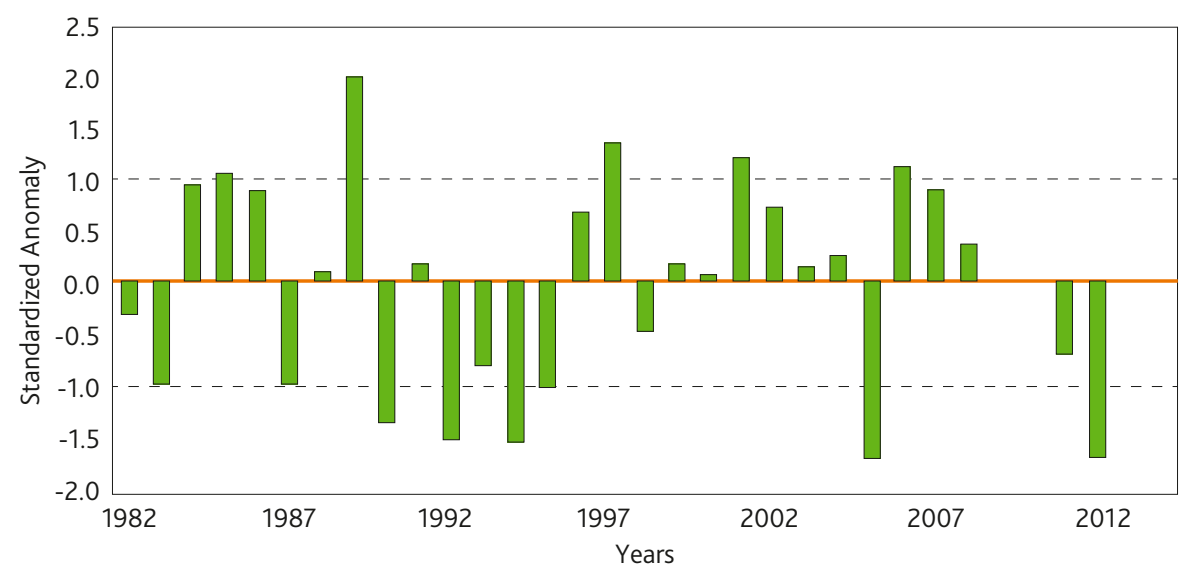

Figure 7. Standardized rainfall anomalies over Malawi for the period 1982 - 2012 
dryness (Ogwang, et al., 2012). Ongoma et al. has also used this methodology to classify precipitation intensity (Ongoma, et al., 2016).

\section{ETCCDI Indices over Malawi}

\section{Frequency indices}

The first part of the extreme indices experiments was to determine the frequency of extreme rainfall over Malawi. Understanding the frequency of extreme rainfall is cardinal as it can give an understanding of the return period of a given event i.e. the probability of a given event of equal to or greater magnitude occurring in any given time frame (Bradshaw, et al. ing winds, lighting and flooding. For instance, in a study on evidence that deforestation amplifies flood risk and severity in the developing world, Bradshaw et al. (2007) used the duration of a flood, the number of lives lost, the number of people displaced and estimated total damage to describe the intensity of a flood.

In this study, a significant increasing trend of daily maximum rainfall (Rxiday $j=\max (R R i j)$ has been observed over Karonga in the north and Bvumbwe in the south. Six other stations i.e. Ngangu, Chichiri, Mangochi, Dedza, Kamuzu International Airport (KIA), and Salima exhibited an increasing insignificant trend while all the other stations showed that daily maximum rainfall is reducing insignificantly (figure 9a).
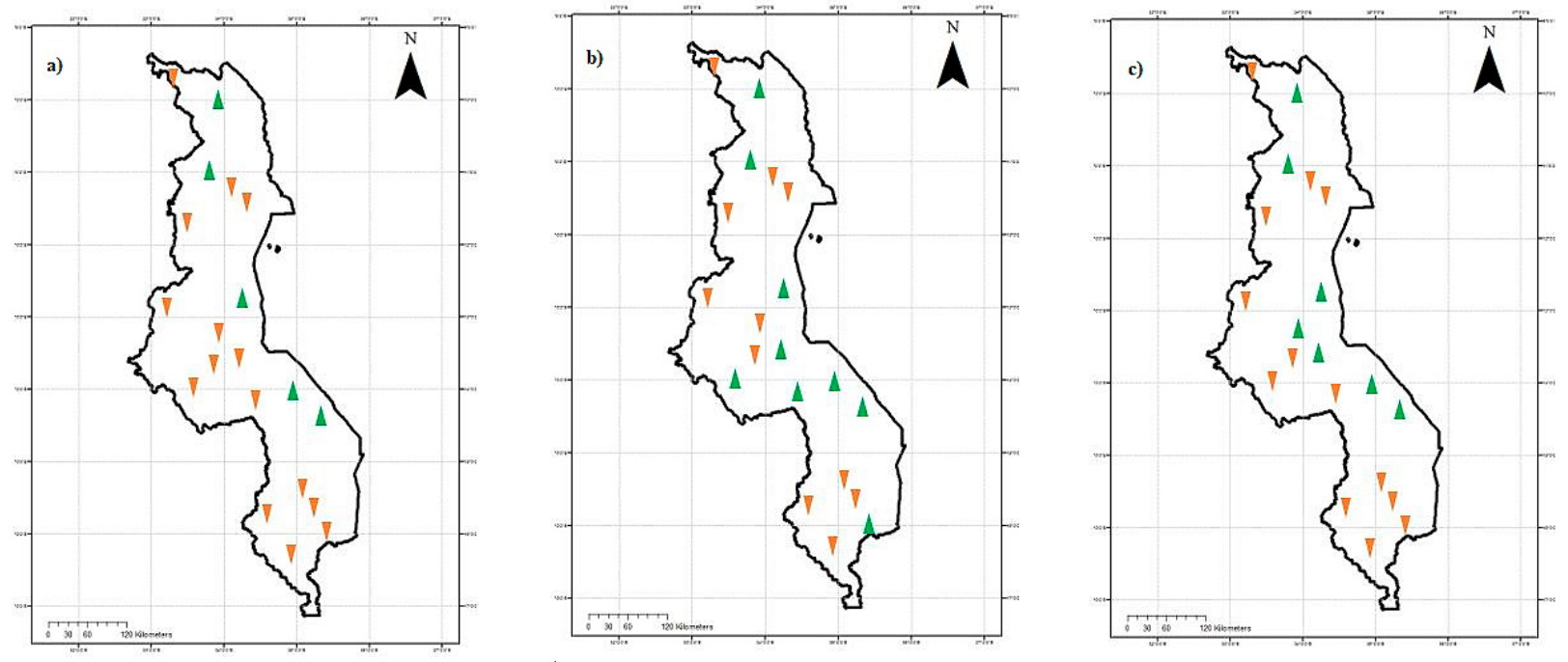

Figure 8. shows Trend of a) heavy rainfall days (RRij $\geq 10 \mathrm{~mm}$ ); b) very heavy rainfall days (RRij $\geq 20 \mathrm{~mm}$ ) and c) extremely heavy rainfall days (RRij $\geq 25 \mathrm{~mm}$ ). The green up right triangles signify insignificant upward trend while the upside-down orange triangles signify a downward trend

2007). Results (figure 8a) show that apart from Karonga, Bolero, Nkhata Bay, Nkhota Kota, Monkey Bay, and Mangochi all the other stations observed a decreasing trend in the frequency of heavy rainfall days (RRij $\geq 10 \mathrm{~mm})$. One interesting find is that all the stations that experienced an increasing trend are located on the eastern part of Malawi (figure 1) towards Lake Malawi. Changes in very heavy rainfall days (figure $8 b$ ) and extremely heavy rainfall days (figure 8c) were not concentrated on any given location; wide variations have been observed from station to station. All these rainfall frequency results are insignificant at $5 \%$ significance level.

\section{Intensity indices}

Another significant part that was considered and is documented herein is the intensity of rainfall. Many studies have described the intensity of a given wet event by considering the effects of the accompany-
Figure $9 \mathrm{~b}$ shows 5-day maximum rainfall ( $\mathrm{Rx} 5$ day $\mathrm{j}=\max ($ RRij ); again Bvumbwe experienced a significant positive trend but a complete reversal was seen over Karonga which experienced an insignificant negative trend.

Three stations showed significant trends in very wet days (R95p). Chileka and Mzimba, on the western parts of the country experienced a significant decreasing trend while Thyolo had a significant increasing trend (figure 9c).

Figure $8 \mathrm{~d}$ shows that Chileka was the only station in the country that received a significant trend (decreasing) in very wet days (R99p)

Results of simple daily intensity are given in figure 10a. Thyolo was the only station that received a significant increasing trend in the annual mean rainfall when PRCP $\geq 1 \mathrm{~mm}$ (SDII). All the other results were insignificant at the $5 \%$ confidence level. Notably, the eastern parts of the country received an increas- 

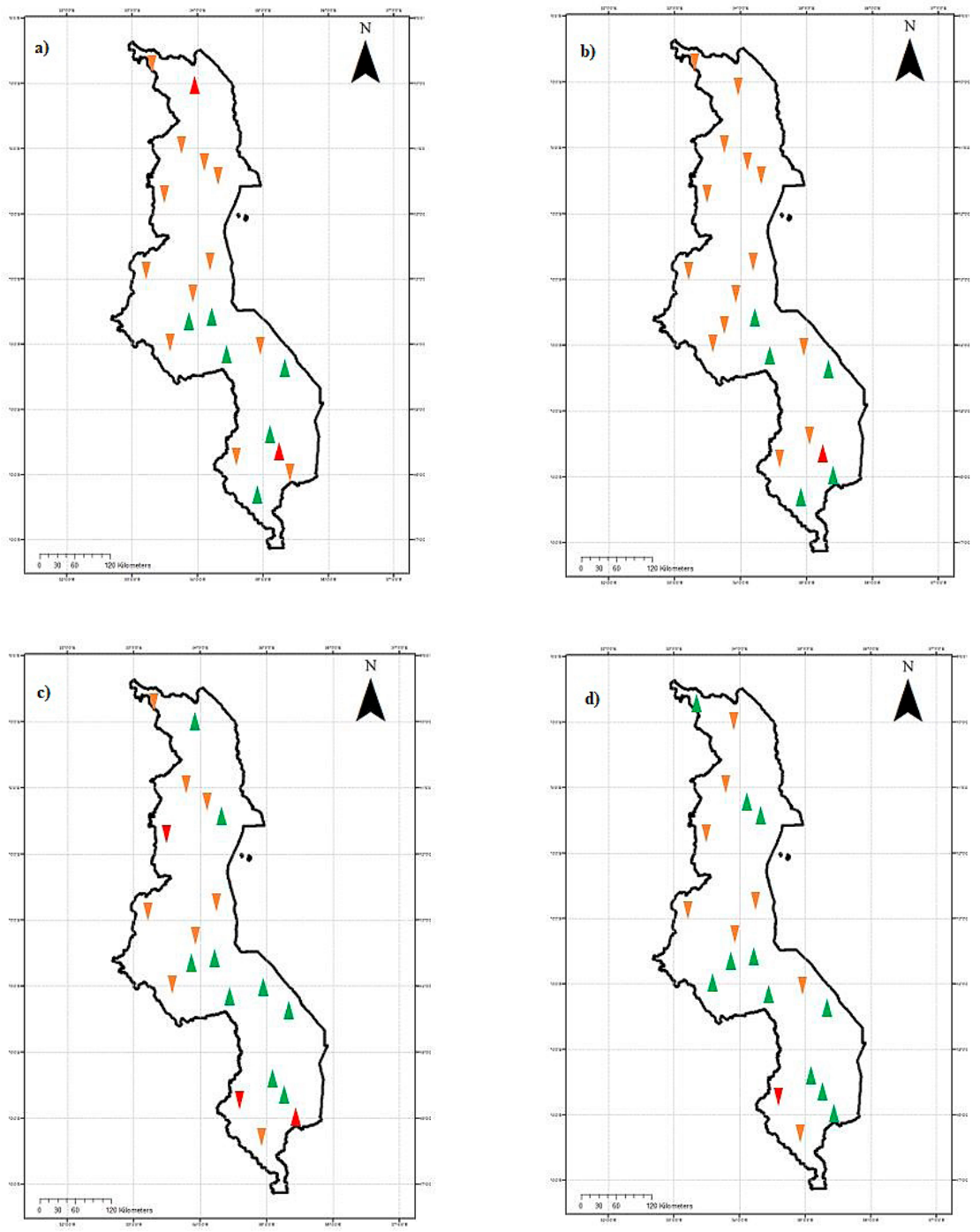

Figure 9. shows Trend of a) daily maximum rainfall (Rx1day); b) 5-day maximum rainfall; c) very wet days (R95p) and d) extremely wet days (R99p). The green up right triangles signify insignificant upward trend while the upside-down orange triangles signify an insignificant downward trend. Red triangles signify significant trends
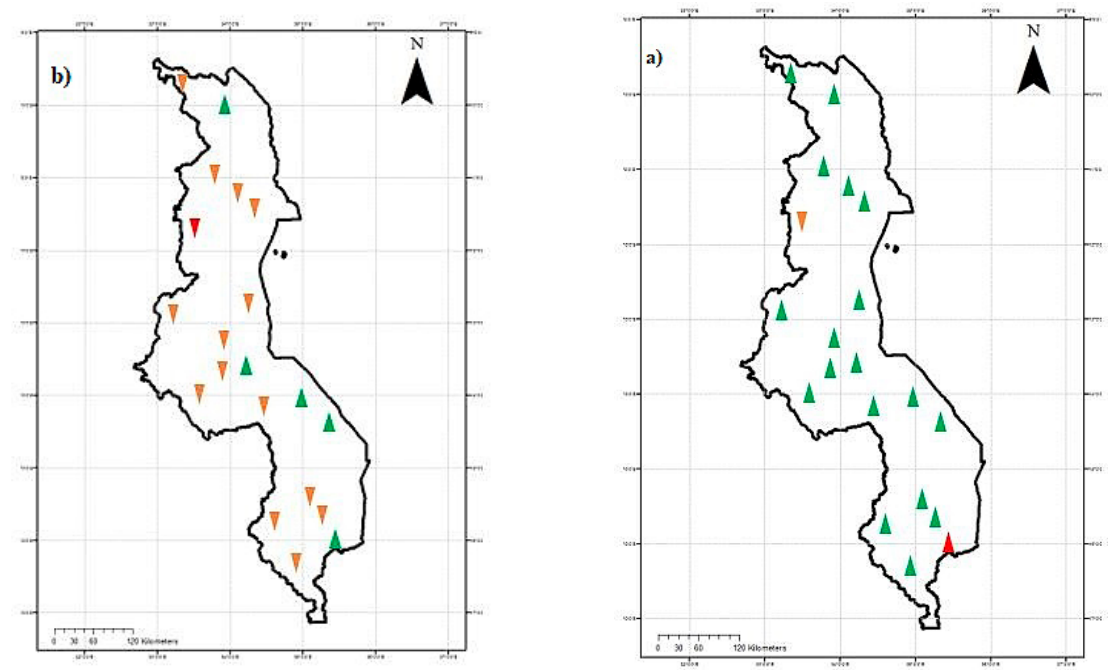

Figure 10. shows Trend of a) Simple daily intensity (SDII) and b) Total rainfall in wet days (PRCPTOT). The green up right triangles signify insignificant upward trend while the upside-down orange triangles signify an insignificant downward trend. Red triangles signify significant trends 
ing trend whereas the western parts of the country observed a decreasing trend. Figure 1ob shows annual total rainfall in wet days ( $R R>1 \mathrm{~mm})$. A significant decreasing trend was observed over Mzimba while insignificant increasing and decreasing changes, different from station to station were observed over the rest of the country.

\section{Conclusion and Recommendations}

The variability of extreme wet events over Malawi was analysed using indices of the Expert Team on Climate Change Detection and Indices (ETCCDI), a joint team of the World Meteorological Organization (WMO), Climate Change Initiative (CCl), Climate Variability and Predictability (CLIVAR) and the Joint Technical Commission for Oceanography and Marine Meteorology (JCOMM). The daily rainfall data used was kindly provided by Malawi Department of Climate Change and Meteorological Services. The data covers a period of thirty years from 1982 - 2012 and is sourced from 21 Meteorological Stations widely spread over the whole country. However, the datasets for Thyolo Meteorological Station only spans over a period of 27 years from 1982 - 2009. Mimosa was not included in further analysis as the homogeneity tests showed that it was inhomogeneous. It has been observed that generally the northern parts of the country, together with eastern African countries, experience extreme wetness during El Nino years while the southern parts experience extreme dryness. During La Nina years however, the southern half of the country together with southern African countries (e.g. Zambia) experience extreme wetness while the northern parts and eastern African countries experience extreme dryness (Ngongondo, et al., 2006). This observation will be key for agricultural tactical purposes especially considering that most models project wetness on the northern half of the country and dryness on the southern half. Indices results indicate large temporal and spatial variability in trends. Notably, only five stations have observed significant trends - all increasing significant trends were observed over Thyolo (SDII and R95p), Bvumbwe (Rx1day and Rx5day) and Karonga (Rxiday) while significant decreasing trends were observed over Chileka (R95p and R99p) and Mzimba (PRCPTOT and R95P). The more rainfall received over the eastern parts of the country has been linked to the contribution that Lake Malawi makes over areas near it. More evaporation from lake Malawi as compared to land surface enhances cloud formation and rainfall over the eastern areas of the country. During wet years, Malawi is characterised by an anomalous convergence of strong south-easterly and north-easterly winds.
This convergence is the main rain bringing mechanism to Malawi. Results of Pearson's correlation between Mean DJF wind anomaly vectors () at $850 \mathrm{hpa}$ and mean rainfall over Malawi show stronger correlation along the eastern parts of the country and weakens west-wards hence contributing to more precipitation on the eastern than on the western parts of the country. This paper recommends that longer datasets (with more stations) be used to investigate if this trend will still be prevalent. It is further recommended that projections be employed and studied to check if this eastern-western trend will still be noticeable; these studies can aid in water resources management planning and flood risk strategies.

\section{Acknowledgements:}

The authors are thankful to Newcastle University and the Commonwealth Scholarship Council for the funds and statistical tools used in this study. Malawi Department of Climate Change and Meteorological Services is acknowledged for the daily rainfall data.

\section{References}

Alexandersson, H., Moberg, A. 1977. Homogenization of Swedish temperature data. Part I: homogeneity test for linear trends. International Journal of Climatology 17, 25-34. doi:10.1002/(SICI)10970088(199701)17:1<25::AID-JOC103>3.0.CO;2-J

BBC. 2015. Malawi floods kill 170 and leave thousands homeless - BBC News, Available at: http://www. bbc.co.uk/news/world-africa-30854140, (6.6.2017).

Benin, S., Thurlow, J., Diao, X., McCool, C., Simtowe, F. 2008. Agricultural growth and investment options for poverty reduction in Malawi. IFPRI Discussion Paper No. 00794, Available at: http://ebrary. ifpri.org/cdm/ref/collection/p15738coll2/id/13440.

Benson, C., Clay, E., 1998. Drought and Sub-Saharan African Economies. Africa Region Findings \& Good Practice Infobriefs; No. 118. World Bank, Washington, DC.

Bouwer, L. 2011. Have Disaster Losses Increased Due to Anthropogenic Climate Change? Bulletin of the American Meteorological Society 92-1, 39-46.

Bradshaw, C., Sodhi, N., Peh, K., Brook, B. 2007. Global evidence that deforestation amplifies flood risk and severity in the developing world. Global Change Biology 13-11, 2379-2395.

Christensen, J. 2007. Climate change 2007: the physical science basis. Contribution of Working Group I to the Fourth Assessment Report of the Intergovernmental Panel on Climate Change, Cambridge: Cambridge University Press, chapter Regional climate projections, 847-940. 
Davies, R. 2017. Malawi - Floods in Karonga District Leave 4 Dead, Crops Destroyed - Flood List. Available at: http://floodlist.com/africa/malawi-floodskaronga-april-2017 ( 30.05.2017).

González-Rouco, J., Jiménez, J., Quesada, V., Valero, F. 2001. Quality Control and Homogeneity of Precipitation Data in the Southwest of Europe. Journal of Climate 14-5, 964-978.

Hoell, A., Funk, C., Magadzire, T., Zinke, J., Husak, G. 2014. El Niño-Southern Oscillation diversity and Southern Africa teleconnections during Austral Summer. Climate Dynamics 45-5-6, 1583-1599.

IPCC. 2012. Managing the risks of extreme events and disasters to advance climate change adaptation. A special report of working groups I and II of the intergovernmental panel on climate change. Cambridge University Press, Cambridge, 996 pp.

IPCC. 2014. Climate change (2007): synthesis report. Contribution of working groups I, II and III to the fifth assessment report of the intergovernmental panel on climate change. Cambridge University Press, Cambridge, 996 pp.

IPCC. 2001. Climate Change: The Scientific Basis. Contribution of Working Group 1 to the Third Assessment report of the Intergovernmental Panel on Climate Change. International Journal of Epidemiology 32-2, 321-321.

IPCC. 2013. Climate Change: The Physical Science Basis. Contribution of Working Group I to the Fourth Assessment Report of the Intergovernmental Panel on Climate Change.

Javari, M. 2016. Trend and Homogeneity Analysis of Precipitation in Iran. Climate 4-3, 44 pp.

Juma, B. 2017. Malawi - Floods in Northern Region Leave Several Dead and Force Thousands to Evacuate - FloodList. Available at: http:/floodlist.com/ africa/malawi-floods-mzuzu-karonga-april-2016 (30.05.2017).

Jury, M. 2013. Variability in the Tropical Southwest Indian Ocean and Influence on Southern African Climate. International Journal of Marine Science,3-7, 46-64.

Jury, M., Gwazantini, M. 2002. Climate variability in Malawi, part 2: sensitivity and prediction of lake levels. International Journal of Climatology,22-11, 1303-1312.

Kang, H.M., Fadhilah, Y. 2012 Homogeneity Tests on Daily Rainfall Series in Peninsular Malaysia. International Journal of Contemporary Mathematical Sciences 7-1, 9 - 22.

Karl, P., Thurlow, J., Seventer, D.V. 2010. Droughts and Floods in Malawi Assessing the Economywide Effects. IFPRI Discussion Paper No. 00962 Available at: http://www.ifpri.org/publication/droughts-andfloods-malawi (30.05.2017).
Karl, T.R., Nicholls, N., Ghazi, A. 1999. CLIVAR/ GCOS/WMO workshop on indices and indicators for climate extremes: workshop summary. Climate Change 42, 3-7. DOI:10.1023/A:1005491526870

Kaser, G. Hardy, D. Mölg, T. Bradley, R., Hyera, T. 2004. Modern glacier retreat on Kilimanjaro as evidence of climate change: observations and facts. International Journal of Climatology, 24-3, 329-339.

Kazembe, A., 2014. Determining the onset and cessation of seasonal rains in Malawi. Postgraduate thesis submitted to the Department of Meteorology, School of Physical Sciences, University of Nairobi. Available at: http://erepository.uonbi. ac.ke/bitstream/handle/11295/95407/Kazembe Determining\%2othe\%2oonset\%2oand\%2ocessation\%20of\%2oseasonal\%2orains\%2oin\%2oMalawi. pdf? sequence $=1$ \&is Allowed $=y$

Kendall, M.G. 1975. Rank correlation methods, 4th edn. Griffin, London

Kumbuyo, C., Yasuda, H., Kitamura, Y., Shimizu, K. 2014. Fluctuation of rainfall time series in Malawi: An analysis of selected areas. Geofizika 31-1, 13-28.

Lee, G., Helling, C., Dobbs-Dixon, I., Juncher, D., 2015. Modelling the local and global cloud formation on HD 189733b. Astronomy \& Astrophysics, 580, A12.

Libanda, B., David, A., Banda, N., Wang, L., Ngonga, C., Linda, N. 2017. Predictor Selection Associated with Statistical Downscaling of Precipitation over Zambia. Asian Journal of Physical and Chemical Sciences 1-2, 1-9. DOI: 10.9734/AJOPACS/2016/31545

Libanda, B., Nkolola, B., Musonda, B. 2015a. Rainfall Variability over Northern Zambia. Journal of Scientific Research \& Reports 6-6, 416-425. DOI:10.9734/ JSRR/2015/16189

Libanda, B., Ogwang, B.A., Ongoma, V., Chilekana, N., Nyasa, L. 2015b. Diagnosis of the 2010 DJF flood over Zambia. Natural Hazards 81, 189-201. DOI 10.1007/s11069-015-2069-Z

Loomis, R. 1999. Feeding a World Population of More than Eight Billion People: A Challenge to Science. Crop Science 39-4, 1250 pp.

Majidi, M., Alizadeh, A., Farid, A., Vazifedoust, M. 2015. Estimating Evaporation from Lakes and Reservoirs under Limited Data Condition in a Semi-Arid Region. Water Resources Management 29-10, 3711-3733.

Mann, H.B. 1945. Non-parametric tests against trend. Econometrica 13, 245-259.

Metmalawi, 2017. Malawi Meteorological Services. Available at: http://www.metmalawi.com/climate/ climate.php (28.05.2017).

Mokrech, M., Kebede, A.S., Nicholls R.J., Wimmer, F., Feyen, L. 2014. An integrated approach for assessing flood impacts due to future climate and socioeconomic conditions and the scope of adaptation in Europe. Climatic Change 128-3-4, 245-260. 
ND-GAIN, 2017. Malawi | ND-GAIN Index. Available at: http://index.gain.org/country/malawi (7.6.2017).

Ngongondo, C. 2006. An analysis of long-term rainfall variability, trends and groundwater availability in the Mulunguzi river catchment area, Zomba mountain, Southern Malawi. Quaternary International 148-1, 45-50.

Ngongondo, C., Xu, C., Gottschalk, L., Alemaw, B. 2011. Evaluation of spatial and temporal characteristics of rainfall in Malawi: a case of data scarce region. Theoretical and Applied Climatology 106-1-2, 79-93.

Ngwira, A., Aune, J., Thierfelder, C. 2014. DSSAT modelling of conservation agriculture maize response to climate change in Malawi. Soil and Tillage Research, 143, 85-94.

Nicholas, N., Wassila, T. 2017. Available at: http://www. cpc.ncep.noaa.gov/products/fews/AFR_CLIM/ AMS_ARC2a.pdf (30.052017).

Nicholson, S. 2000. The nature of rainfall variability over Africa on time scales of decades to millenia. Global and Planetary Change 26-1-3, 137-158.

Nicholson, S., Klotter, D., Chavula, G. 2013. A detailed rainfall climatology for Malawi, Southern Africa. International Journal of Climatology 34-2, 315-325.

Nicholson, S.E., Yin, X. 2002. Mesoscale patterns of rainfall, cloudiness and evaporation over the Great Lakes of Africa. In: Odada, E.O., Olago, D.O. [eds.], The East African Great Lakes: Limnology, Palae- olimnology and Biodiversity (pp. 93-119). Kluwer Academic Publishers, Dordrecht, Holland.

Ogwang, B.A., Guirong, T., Haishan, C. 2012. Diagnosis of September - November drought and the associated circulation anomalies over Uganda. Pakistan Journal of Meteorology 9-17, 11-24.

Ongoma, V., Chen, H., Omony, G. 2016. Variability of extreme weather events over the equatorial East Africa, a case study of rainfall in Kenya and Uganda. Theoretical and Applied Climatology (First online).doi:10.1007/s00704-016-1973-9

Sen P.K. 1968. Estimates of the regression coefficient based on Kendall's Tau. Journal of American Statistical Association 63, 1379-1389. doi:10.2307/2285891

Vörösmarty, C., McIntyre, P., Gessner, M., Dudgeon, D., Prusevich, A., Green, P., Glidden, S., Bunn, S., Sullivan, C., Liermann, C., Davies, P., 2010. Global threats to human water security and river biodiversity. Nature 467-7315, 555-561.

Westra, S., Fowler, H., Evans, J., Alexander, L., Berg, P., Johnson, F., Kendon, E., Lenderink, G., Roberts, N. 2014. Future changes to the intensity and frequency of short-duration extreme rainfall. Reviews of Geophysics 52-3, 522-555.

Zaroug, M., Eltahir, E., Giorgi, F. 2014. Droughts and floods over the upper catchment of the Blue Nile and their connections to the timing of El Niño and La Niña events. Hydrology and Earth System Sciences 18-3, 1239-1249. 